\title{
PRINCIPAIS MADEIRAS UTILIZADAS PARA LAMINAÇÃO NA REGIÃO DE CURITIBA, PR
}

\section{MAIN SPECIES USED IN VENEER PRODUCTION IN CURITIBA, PR}

\author{
Silvana NISGOSKI ${ }^{1}$ \\ Graciela Inés Bolzon de MUÑIZ² \\ Umberto $\mathrm{KLOCK}^{3}$
}

\begin{abstract}
RESUMO
Este trabalho trata da identificação das principais madeiras utilizadas para laminação na região de Curitiba, Paraná, assim como da variação na sua nomenclatura popular, visando à correta identificação. Foram coletadas 72 amostras de lâminas faqueadas e torneadas de espécies escolhidas com base no uso mais freqüente e importância de utilização. Pela dificuldade apresentada nas análises macroscópicas, devido às características do material amostrado, a identificação teve que ser baseada em características peculiares e marcantes de cada espécie. Foram identificadas 37 espécies. Ficou constatado que existe uma distorção entre os nomes comerciais e a nomenclatura associada ao nome científico, existente na maior parte das fontes. A constatação de erros na identificação das madeiras ressalta a necessidade de adoção de uma técnica de identificação, com base na estrutura anatômica do lenho, e da padronização da nomenclatura comercial das madeiras, considerados os documentos elaborados por órgãos idôneos, como as publicações do IBAMA.
\end{abstract}

Palavras-chave: características anatômicas, laminação, nomenclatura.

\begin{abstract}
This work is about identifying the species used in veneer production in Curitiba, Parana State, Brazil, and popular names variation, so as to be identified correctly. Seventy two sliced veneers and rotary cut veneers samples, from species based on frequency and utilization importance, were collected. Because of samples characteristics, the identification was based in peculiar structures. Thirty seven species were identified. Incorrect commercial names in association to botanical names were verified. Identification technics adoption, based on anatomic characteristics, and nomenclature standard, using papers made by competent members, are necessary.

Key-words: anatomic characteristics, veneer production, nomenclature.
\end{abstract}

\footnotetext{
Engenheira Florestal, M.Sc. UFPR. Escola de Florestas. DETF. Bolsista CAPES. Av. Pref. Lothario Meissner, 3400. Jardim Botânico. 80.210170. Curitiba, PR.silnis@yahoo.com @ Autor para correspondência.

2 Engenheira Florestal, Dr. Professora Titular, Departamento de Engenharia e Tecnologia Florestal, UFPR.

3 Engenheiro Florestal, M.Sc. Professor Assistente. Departamento de Engenharia e Tecnologia Florestal, UFPR.
} 


\section{INTRODUÇÃO}

Grande parte da madeira laminada consumida no Brasil provém de espécies oriundas da região Amazônica. As toras ou as próprias lâminas chegam às empresas com nomes populares comuns a cada local, sendo que muitas vezes existem várias espécies com a mesma denominação. Cada espécie apresenta características individuais, que determinam a possibilidade de emprego para uma ou outra finalidade. Embora o nome seja semelhante, as propriedades podem ser totalmente diferentes, o que pode ocasionar diversos problemas quando a madeira é utilizada. O conhecimento do nome correto, das características anatômicas, botânicas e das propriedades em geral permite predizer quais são os melhores usos da madeira de cada espécie, evitando gastos desnecessários e problemas futuros.

De acordo com o IBAMA (1991), a nomenclatura popular é reconhecidamente um dos pontos mais importantes na comercialização de madeiras tropicais. A utilização de múltiplos nomes para uma mesma madeira, bem como a existência de diferentes madeiras comercializadas sob um mesmo nome, tem provocado problemas com os consumidores.

Segundo um estudo do IBDF (1985), há três razões que podem gerar o uso de nomes incorretos: presença de características semelhantes entre madeiras diferentes, uso de nomes de espécies já conhecidas visando facilitar a comercialização e uso de uma característica da madeira para designar seu nome.

De acordo com Keenam e Tejada (1984), a utilização adequada das espécies de madeira depende de procedimentos que garantam a identificação das mesmas, quer seja como árvores, toras ou madeira processada. Chimelo e Alfonso (1985) apontam a identificação como base dos estudos de caracterização da madeira e sua utilidade no comércio, ao qual propicia meios para se detectar enganos e fraudes.

O desenvolvimento de novas tecnologias de transformação da madeira, as pressões ambientalistas e o constante aumento da consciência para utilização dos recursos florestais renováveis, levam o setor moveleiro e de construção civil a buscar espécies alternativas para seu abastecimento.

Toda a literatura existente sobre espécies utilizadas comercialmente está baseada em madeira serrada (IBDF, 1985; ABPM, 1989; IPT, 1993; Ozório Filho e Alfonso, 1995; Zenid, 1997). A espessura e orientações de corte das lâminas causam dificuldades de observação das características anatômicas, o que justifica, em parte, a ausência de trabalhos com este material. No caso de lâminas faqueadas, para que se tenha uma superfície adequada para visualização das estruturas componentes da madeira, são necessárias várias lâminas, cortadas seqüencialmente, as quais são unidas para formar um bloquinho com tamanho suficiente para a identificação científica do material.

Este trabalho teve como objetivo identificar as principais espécies de madeira utilizadas no mercado de lâminas na região de Curitiba, além de avaliar a variação na nomenclatura popular de uma espécie, para evitar fraudes ou enganos.

\section{METODOLOGIA}

Foram enviados questionários a todas as empresas de Curitiba, PR, que, de alguma forma, utilizam lâminas de madeira, seja produção própria ou adquiridas de terceiros, obtendo-se informações das espécies utilizadas, padronização da qualidade e tratamento preservativo, bem como principais problemas encontrados.

Por meio de visitas, foram coletadas 72 amostras de lâminas faqueadas e torneadas nas empresas que apresentavam maior variabilidade de espécies e dispuseram-se a fornecer o material. No caso de lâminas faqueadas, cada amostra coletada foi composta por determinado número de lâminas cortadas seqüencialmente, ou seja, quando unidas forneciam a imagem da superfície do lenho antes do corte. O nome fornecido pela empresa foi anotado em cada amostra.

As amostras coletadas nas empresas de Curitiba foram identificadas no Laboratório de Anatomia da Madeira, da Universidade Federal do Paraná (UFPR). Esta identificação foi realizada pelo exame das características do lenho, primeiramente pelo processo macroscópico, com o auxílio de uma lupa contafios de aumento 10x. Como padrão foram utilizadas as amostras da xiloteca do próprio laboratório.

Quando esta análise não foi suficiente, utilizou-se o processo microscópico, que exige a preparação de seções histológicas para observação em microscópio óptico, sendo utilizadas como padrão as lâminas disponíveis no laminário do próprio laboratório. Caso este procedimento não fosse possível, seguiriam-se as descrições anatômicas disponíveis na literatura.

Para confirmação das identificações, amostras foram enviadas para o Laboratório de Produtos Florestais (LPF/DIREN/IBAMA), em Brasília, DF.

Pelos processos empregados neste trabalho, não foi possível a identificação da espécie de algumas amostras. Nestes casos, fez-se necessário o exame de órgãos vegetativos (flores e folhas) para auxiliar na sua identificação.

Com a obtenção do nome científico, após a identificação, foi dado a cada amostra seu nome comercial correspondente, utilizando-se como critério a "Padronização da nomenclatura comercial brasileira das madeiras tropicais amazônicas" (IBAMA, 1991) e o "Catálogo de árvores do Brasil" (Camargos et al. 1996). 


\section{RESULTADOS E DISCUSSÃO}

A avaliação das características anatômicas do lenho das amostras coletadas permitiu a identificação botânica das mesmas, apresentada em relação ao nome comercial utilizado na região de Curitiba (Tabela 1).

Além dessas madeiras, também são utilizadas lâminas de marinheiro, sumaúma, virola, figueira-branca e rosa, caucho, jacareúba, garapeira, angelim, copaíba, mas, como a quantidade comercializada é pequena, não havia amostras disponíveis.

Pela observação da Tabela 1 pode-se verificar que, em alguns casos, como por exemplo no amapá, cedro, curupixá, pau-marfim, mogno e tauari, o mesmo nome comercial é utilizado para madeiras pertencentes a gêneros e espécies diferentes. Estas confusões possivelmente são causadas, em parte, por verdadeiro desconhecimento do material utilizado, mas, também pela tentativa de fraude, utilizando-se uma madeira de menor valor no lugar de uma altamente valorizada, cobrando-se o maior preço, ou pelo esforço de comercialização de novas espécies de madeira. No caso das lâminas, fica muito mais difícil para um leigo diferenciar as espécies, daí a necessidade de uma correta avaliação do material. Nota-se que as maiores confusões estão no mogno, pau-marfim, amapá e tauari, espécies de alto valor comercial e, no caso dos dois primeiros, de exploração controlada.

Observando-se a listagem dos outros nomes comerciais fornecidos, verifica-se a existência do nome koto, que é de uma madeira africana, pertencente ao gênero Pterygota, da família Sterculiaceae, aplicado a uma madeira que, de acordo com o IBAMA, recebe o nome de muiratinga (Maquira guianensis), com características anatômicas bem diferentes, o que caracteriza um grande erro de nomenclatura e possivelmente tem conseqüências no seu emprego.

Observando-se os dados anteriores, podese notar que foram identificadas 37 espécies distintas nas madeiras de diferentes procedências, colhidas na região de Curitiba, sob forma de lâminas. Além de espécies amazônicas e da Mata Atlântica, pode-se verificar a presença de espécies de reflorestamento, como o pinus e o eucalipto, e madeiras importadas, como o sapele e o carvalho.

Foram fornecidos 34 nomes comerciais, enquanto nas amostras coletadas foram identificados em laboratório 54 táxons, com 27 gêneros e 30 espécies diferentes. O uso de uma quantidade de nomes comerciais menor que a totalidade de nomes sugeridos pelo IBAMA, que neste trabalho atinge 49 , indica a tendência à simplificação do mercado, o que pode ser resultado de uma simples confusão, pela falta de conhecimento e agrupamento de espécies com cores semelhantes, ou da tentativa de induzir o consumidor a acreditar que o material fornecido corresponde mesmo à madeira que realmente merece aquele nome.

Verifica-se que em $42,6 \%$ dos casos os nomes comerciais foram corretamente aplicados, ou seja, são compatíveis com os nomes sugeridos para o material identificado cientificamente.

Observando-se a variação entre o nome comercial fornecido e o nome científico identificado, nota-se que $64,7 \%$ dos nomes comerciais fornecidos foram aplicados a apenas um gênero ou espécie; $20,59 \%$ a dois; $5,88 \%$ a três; $2,94 \%$ a quatro e cinco gêneros ou espécies diferentes. Também observa-se que nem todos os nomes populares correspondentes a apenas uma espécie são compatíveis com aqueles sugeridos e aplicados pelo IBAMA, como é o caso da cerejeira imperial, marfim do norte e mogno real.

Há nomes como o mogno que foram empregados para cinco espécies diferentes, de vários gêneros da família Meliaceae, e também de outra família, como é o caso do louro-vermelho (Nectandra rubra), uma Lauraceae. O engano dentro da mesma família pode ter origem na semelhança das árvores e madeiras, mas no caso do lourovermelho deve ter tido início na serraria, gerando uma cadeia, uma vez que as árvores são diferentes.

O nome amapá, por exemplo, foi empregado para três espécies, pertencentes a três famílias diferentes; já os nomes tauari e pau-marfim corresponderam a três espécies de duas famílias diferentes, erros possivelmente causados pela semelhança da madeira aliada ao desconhecimento de características peculiares do material.

Também pode-se observar a substituição de espécies, como é o caso da caxeta, típica da Mata Atlântica (Tabebuia cassinioides - Bignoniaceae), que ficou escassa e encontra eqüivalência em madeiras claras e leves na Região Norte do país, tendo seu nome aplicado, por exemplo, a espécies do gênero Simarouba e algumas da família Moraceae.

O inverso também ocorre, como no caso do gênero Simarouba, representado aqui por duas espécies, S. amara e S. versicolor, cujo nome popular adequado é marupá, que pode receber quatro nomes diferentes (amapá, caxeta, marupá e marfim-branco). $\mathrm{O}$ uso de alguns dos nomes incorretos pode ter ou não implicações sérias. No caso do emprego dos nomes caxeta e amapá, também está se tratando de um grupo de madeiras leves e claras, o que no caso das lâminas representa apenas fins decorativos. No caso de usar Simarouba spp. no lugar de paumarfim (Balfourodendron riedelianum), estaria se oferecendo uma lâmina de madeira leve, de baixa densidade e, portanto, baixa resistência mecânica, 
NISGOSKI, S. et al. Principais madeiras utilizadas...

TABELA 1 - Espécies de madeira identificadas nas amostras coletadas nas empresas de laminação de acordo com o nome comercial fornecido, em Curitiba, PR, 1999

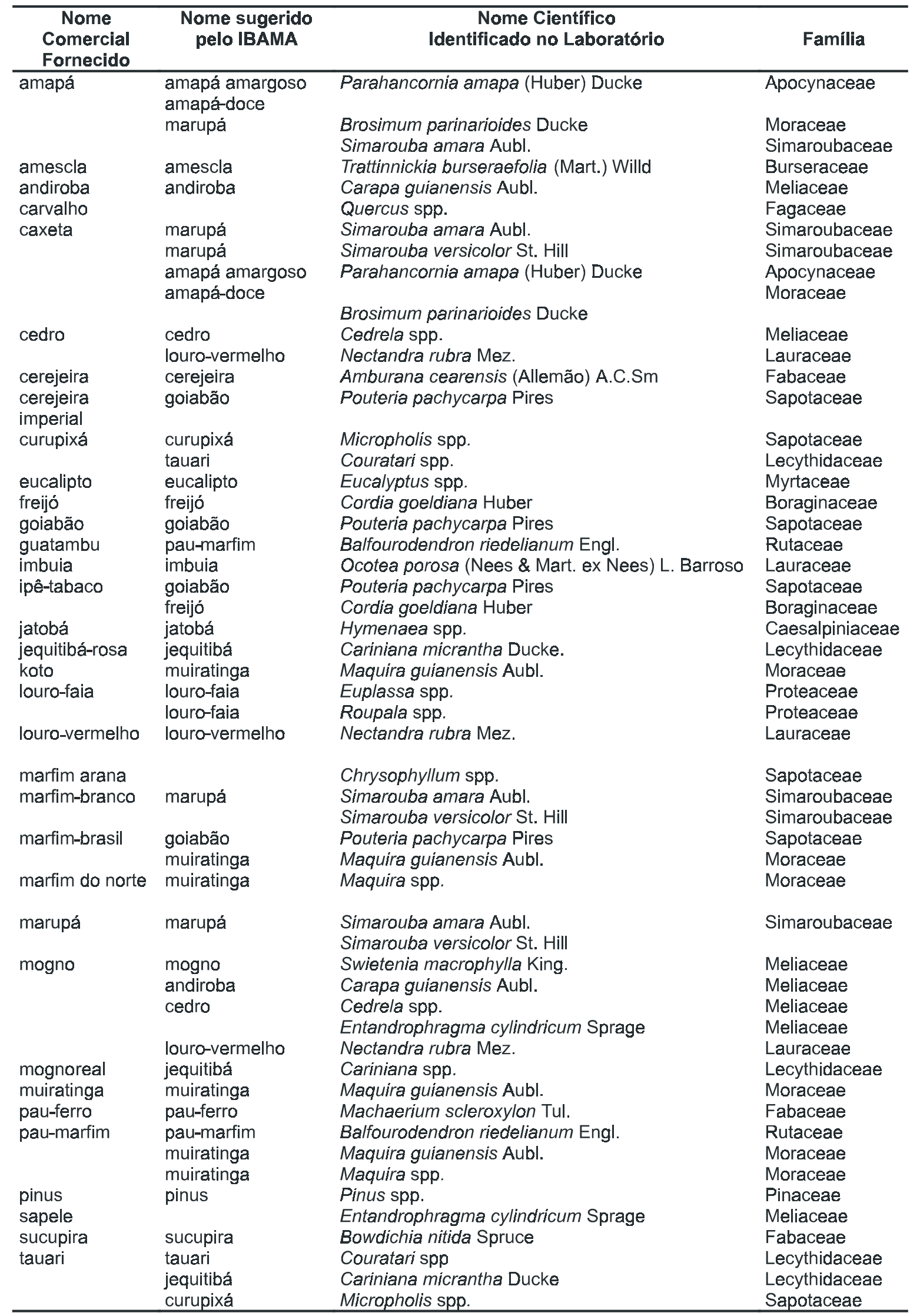


em lugar de uma madeira mais densa, de maior resistência mecânica, principalmente ao impacto e abrasão (por exemplo, seriam encontrados problemas no caso de carpetes de madeira) (Mainieri e Chimelo, 1989).

Pelos resultados obtidos, observou-se que a família Meliaceae contribui com quatro gêneros utilizados para a laminação, sendo a mais significativa. Logo em seguida, a família Fabaceae e Sapotaceae, com três, Lauraceae, Lecythidaceae, Moraceae e Proteaceae com dois cada, Apocynaceae, Boraginaceae, Burseraceae, Caesalpiniaceae, Fagaceae, Myrtaceae, Pinaceae, Rutaceae e Simaroubaceae, com apenas um gênero cada família (Tabela 2).

TABELA 2 - Famílias e número de gêneros encontrados nas lâminas identificadas em Curitiba, PR, 1999

\begin{tabular}{lc}
\hline Familia & Número de Gêneros \\
\hline Meliaceae & 4 \\
Fabaceae, Sapotaceae & 3 \\
Lauraceae, Lecythidaceae, Moraceae, Proteaceae & 2 \\
Apocynaceae, Boraginaceae, Burseraceae, Caesalpiniaceae, Fagaceae, & \\
$\quad$ Myrtaceae, Pinaceae, Rutaceae, Simaroubaceae & 1 \\
TOTAL & 27 \\
\hline
\end{tabular}

O pequeno número de famílias e gêneros utilizados pode ser decorrente das características próprias de cada madeira, que muitas vezes não é adequada para a laminação, por possuir, em sua estrutura, elementos que dificultam ou até impedem este processo, ou mesmo que forneça lâminas de qualidade aceitável, mas que apresenta enormes problemas na montagem dos compensados ou revestimento de outros painéis. As características das toras também devem ser consideradas, uma vez que nem todas apresentam forma adequada para laminação, mesmo que as características da madeira sejam favoráveis ou desejáveis.

Na Tabela 3 são apresentadas as freqüências de ocorrência das espécies, em relação ao nome comercial, estando já agrupadas de acordo com o nome científico, na totalidade das amostras coletadas. A muiratinga apresenta o maior número de amostras, contribuindo com $9,72 \%$ do total, seguida por cerejeira e mogno, representando 8,33\%; sucupira, goiabão, cedro e pau-marfim, com 5,56\%; amapá amargoso, curupixá, freijó, jequitibá e tauari

TABELA 3 - Freqüência das espécies encontradas em relação ao número total de amostras coletadas em Curitiba, PR, 1999

\begin{tabular}{lcc}
\multicolumn{1}{c}{ Espécie } & n & Freqüência (\%) \\
\hline Muiratinga & & 9,72 \\
Cerejeira, Mogno & 6 & 8,33 \\
Sucupira, Goiabão, Cedro, Pau-marfim & 4 & 5,56 \\
Amapá, Curupixá, Freijó, Jequitibá, Tauari & 3 & 4,17 \\
$\begin{array}{l}\text { Louro-Faia, Amescla, Jequitibá-Rosa, Eucalipto, Imbuia, } \\
\text { Jatobá, Louro-Vermelho, Pinus. }\end{array}$ & 2 & 2,78 \\
Marfim Arana, Carvalho, Sapele, Pau-Ferro, Andiroba, & 1 & 1,38 \\
$\quad$ Marupá & 72 & 100 \\
\hline TOTAL & & \\
\hline
\end{tabular}

com 4,17\%; louro-faia, amescla, jequitibá-rosa, eucalipto, imbuia, jatobá, louro-vermelho e pinus, com 2,78\%; e outras seis espécies com 1,38\%.

Uma vez que as características anatômicas são semelhantes, madeiras dentro de um gênero apresentam o mesmo valor econômico, não havendo distinção pela falta de conhecimento do material utilizado ou porque as propriedades são muito próximas, ou mesmo por fraude.

\section{CONCLUSÕES E RECOMENDAÇÕES}

1) Foram identificadas 37 espécies de madeira, de diferentes procedências, colhidas na região de Curitiba, sob forma de lâminas. Além de espécies amazônicas e da Mata Atlântica, pode-se observar a presença de espécies de reflorestamento, como o pinus e o eucalipto, e madeiras importadas, como o sapele e o carvalho. 
2) Como foi verificado, na maioria dos casos, devido ao tipo de corte utilizado, as lâminas são irregularmente orientadas, sendo necessários maior atenção e conhecimento das estruturas da madeira para uma identificação correta. Somado a este fato, a identificação das lâminas torna-se mais difícil em virtude das dimensões limitadas do corte transversal, modo como são avaliadas, normalmente, as principais características anatômicas.

3) Verificou-se que, devido, principalmente, ao uso tradicional de algumas madeiras no comércio de móveis, o nome comercial fornecido pelas empresas, muitas vezes, não corresponde à sua identificação científica.

4) Os padrões mogno e marfim, que abrangem lâminas semelhantes em cor e textura, reúnem um grupo de pelo menos seis espécies, sem que todas sejam de fato mogno (Swietenia macrophylla) e pau-marfim (Balfourodendron riedelianum).
5) O mogno foi o responsável pelos maiores erros, encontrando-se com este nome cinco gêneros diferentes, seguido do amapá, caxeta e tauari com três gêneros, e o cedro, curupixá, lourofaia, pau-marfim, marfim-brasil, com dois gêneros distintos.

6) A constatação de erros na identificação das madeiras ressalta a necessidade de adoção de uma técnica de identificação, com base na estrutura anatômica do lenho, e da padronização da nomenclatura comercial das madeiras, com base em documentos elaborados por órgãos idôneos, como as publicações do IBAMA.

7) Também deveria ocorrer uma mudança de mentalidade das pessoas, que, por tradição, acreditam que apenas esta ou aquela madeira apresenta qualidade adequada, fazendo com que o comércio use de artifícios para garantir a venda e aplicação de novas espécies, com propriedades diferentes.

\section{REFERÊNCIAS}

1 ABPM. Perfil de consumo de produtos de madeira; processamento mecânico. São Paulo: ABPM, 1989. 32p.

2 CAMARGOS, J.A.A.; CZARNESKI, C.M.; MEGUERDITCHIAN, I.; OLIVEIRA, D. Catálogo de árvores do Brasil. Brasília: IBAMA, LPF, 1996. 888p.

3 CHIMELO, J.P.; ALFONSO, V.A. Anatomia e identificação de madeiras. In: IPT. Madeira: o que é e como pode ser processada e utilizada. São Paulo: ABPM, 1985. p.23-58 (Boletim ABPM 36).

4 IBAMA. Padronização da nomenclatura comercial brasileira das madeiras tropicais amazônicas. Brasília: IBAMA, 1991. 85p.

5 IBDF. Identificação e agrupamento de espécies de madeiras tropicais amazônicas; síntese. Brasília: IBDF, 1985. $59 p$.

6 IPT. Identificação de espécies de madeira. São Paulo: IPT, 1993. 34p. (Relatório n³1.832).

7 KEENAN, F.J.; TEJADA, M. Tropical timber for building materials in the andean group countries of South America. Ottawa, Ontario: International Development Research Centre-IDRC, 1984. 151p.

8 MAINIERI, C.; CHIMELO, J.P. Fichas de características de madeiras brasileiras. São Paulo: IPT, 1989. 420p.

9 OZÓRIO FILHO, H.L.; ALFONSO, V.A. Identificação anatômica das madeiras utilizadas na Cidade de São Paulo. Instituto de Biociências-USP. 1995. (Relatório Parcial).

10 ZENID, G.J. Identificação e grupamento das madeiras serradas empregadas na construção civil habitacional na cidade de São Paulo. São Paulo: 1997, 170f. Dissertação (Mestrado em Ciência e Tecnologia de Madeiras) - Universidade de São Paulo. 